\title{
Investigation of the effect of air supply on the effective engine performance of a machine-tractor unit under unsteady load
}

\author{
Stanislav S. Sinitsky*, Vladimir M. Medvedev, Ruslan R. Lukmanov, Gennady V. Pikmullin, and Olga I. Makarova
}

Kazan State Agrarian University, 420015 Kazan, Russia

\begin{abstract}
The article discusses the effect of air supply (excess air coefficient) on the effective performance of the engine of a machine-tractor unit with an unsteady load. The analysis of the influence of unsteady load on the engine performance of the machine-tractor unit (MTU) is given. Theoretical studies are presented to determine the effective performance of the MTU engine under unsteady load and their comparative analysis with the results of experimental data. This is necessary to verify the adequacy of theoretical dependencies with the results of experimental studies.
\end{abstract}

\section{Introduction}

One of the first scientists to study the processes taking place in the MTU internal combustion engine (ICE) under operating conditions were: Boltinsky V.N. [1], A. Yuldashev [2, 3], V. I. Krutov [4], Antipin, V. P. [5] and other scientists.

They determined the negative impact of the transient load on the performance of the MTU engine.

Among these indicators are [1]:

1. Resistive torque on the shaft of the tractor engine.

$$
M_{r}=M_{f}+M_{h} \pm M_{\alpha} \mp M_{J}+M_{f r}
$$

where $\mathrm{M}_{\mathrm{r}}$ - the resistive torque on the shaft of the tractor engine, $\mathrm{Nm} ; \mathrm{M}_{\mathrm{f}}$ - the resistive torque to rolling the tractor, $\mathrm{Nm} ; \mathrm{M}_{\mathrm{h}}$ - the resistive torque on the hook of the tractor, $\mathrm{Nm} ; \mathrm{M}_{\alpha}-$ the resistive torque when lifting (lowering) the tractor, $\mathrm{Nm} ; \mathrm{M}_{\mathbf{J}}-$ the resistive torque from inertia forces during acceleration (braking) of the tractor, $\mathrm{Nm} ; \mathrm{M}_{\mathrm{fr}}$ - the resistive torque from friction, $\mathrm{Nm}$.

2. The degree of unevenness of the resistive torque on the motor shaft.

$$
\delta=\frac{M_{r \max }-M_{r \min }}{M_{a v}}
$$

where $\delta-$ is the degree of non-uniformity of the resistive torque on the motor shaft; $\mathrm{M}_{\mathrm{rmax}}$ - the largest value of the resistive torque on the motor shaft, Nm; $\mathrm{M}_{\mathrm{rmin}}$ - the smallest value of the resistive torque on the motor shaft, $\mathrm{Nm} ; \mathrm{M}_{\mathrm{av}}$ - the average value of the resistive torque on the motor shaft, $\mathrm{Nm}$.

3. The period of change of the resistive torque $-\mathrm{T}$, seconds.

4. Overload factor.

$$
K_{\text {over }}=\frac{M_{r \max }}{M_{e \max }},
$$

where $K_{\text {over }}$ - overload fractor; $M_{\mathrm{emax}}-$ maximum torque on the crankshaft of the engine, $\mathrm{Nm}$.

The change in engine torque is described by the formula, [2]:

$$
M_{e}=f\left(\eta_{v} \frac{\eta_{i}}{\alpha} \eta_{m}\right)
$$

During the implementation of agricultural work, scientists recommend under-loading the MTU engine to $20 \%$, and this causes an increased fuel consumption by $10 \ldots 15 \%$ [6-8]. Engine life is being reduced $[9,10]$.

When performing basic agricultural operations, MTU engines operate at an unsteady load close to the maximum $(0.9 \ldots 0.95 \mathrm{Ne})[2,10,11]$.

As noted in [9], power losses during harrowing are $6.5 \%$, when towing $7.1 \%$, and when plowing $17.5 \%$.

Figure 1.1. presents the results of studies of the distribution of resistive torque to MTU during various agricultural operations [2, 3].

The works of A.K. Yuldasheva [2, 3] studied the change in the indicator indicators of a tractor diesel engine (vortex chamber) with a fixed rail of the fuel pump at an unsteady load. It was observed that with an increase in the amplitude of fluctuations in the frequency of rotation of the engine shaft, the engine filling factor $\left(\eta_{v}\right)$, the excess air coefficient $(\alpha)$, the mixture formation and combustion process deteriorate, and this leads to a decrease in the average indicator pressure $\left(\mathrm{P}_{\mathrm{i}}\right)$ and indicator efficiency $\left(\eta_{\mathrm{i}}\right)$, which in turn leads to a decrease in the technical and economic indicators of engines.

The works of V. Antipov [5], A. Yuldashev [2, 3], V. M. Arkhangelsky [12] and other scientists [13-17], devoted to the study of the influence of operating modes engines of mobile vehicles in operating conditions for fuel efficiency and performance, indicated the drop in power and fuel consumption increase.

In the works of Gabdrafikov, F.Z. [18] and Abramov M.A. [19] the operation of a high-pressure fuel pump

* Corresponding author: stanislavsin@mail.ru 
(HPFP) of a diesel engine in dynamic modes was widely considered.

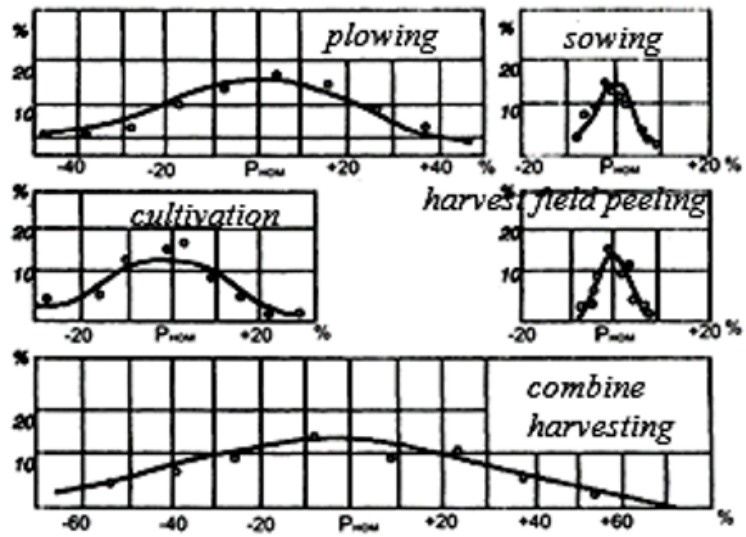

Fig. 1. Graphs of the distribution of MTU resistive torque during various agricultural operations

The main indicator of the HPFP is the cycle feed $\left(g_{T}\right)$. It depends on the speed of the pump shaft and the position of the rail of the fuel pump $\left(h_{R}\right)$.

$$
g_{T}=f\left(n, h_{R}\right),
$$

To obtain the transfer functions that describe the change in the cyclic fuel supply under an unsteady load, the authors note that when the load changes, the speed of the pump shaft changes exponentially on the corrector branch, and the rack position on a periodically damped curve on the regulator branch.

The engine fill factor is affected by a change in air flow. The magnitude of the filling ratio depends on structural, operational factors.

With an increase in angular velocity, a decrease is observed, and with a decrease in an increase in angular velocity, an increase in the filling of cylinders is observed $[3,5,9]$.

The mathematical model of MTU engine performance under an unsteady load along the regulatory branch can be described by differential equations of the second, third and higher ranks.

\section{Materials and methods}

The processes occurring in the MTU engine within the linear zones can be described by linear differential equations with constant coefficients. These equations allow us to describe the processes occurring in the MTU engine under operating conditions.

The determination of the coefficients of differential equations in an analytical way is difficult and not always possible. Therefore, it is proposed to apply the method of numerical solution of differential equations to determine the coefficients taking into account the obtained experimental dynamic characteristics, which will greatly simplify the problem.

When solving linear differential equations, the following assumptions are made:

The study of the dynamic characteristics of the MTU engine is made with allowance for the linear sections of the load characteristic;
The effective performance of the MTU engine is growing with allowance for the requirements of the guests:

GOST 18509 "Tractor and combine diesel engines, bench test methods";

International Standard 1585-82 "Road vehicles, engine test methods, net power".

When studying the dynamic characteristics of the MTU enginethe in regulatory branch, second-order linear differential equations are described:

$$
\begin{aligned}
& T_{2 n}^{2} \frac{d^{2} n}{d t^{2}}+T_{1 n} \frac{d n}{d t}+n_{0}=K_{n 2} \Delta M_{c}, \\
& T_{2 g}^{2} \frac{d^{2} g_{T}}{d t^{2}}+T_{1 g} \frac{d g_{T}}{d t}+g_{T 0}=K_{g 2} \Delta M_{c}, \\
& T_{2 a}^{2} \frac{d^{2} G_{a}}{d t^{2}}+T_{1 a} \frac{d G_{a}}{d t}+G_{a 0}=K_{a 2} \Delta M_{c},
\end{aligned}
$$

where $T_{1 i}, T_{2 i}, T_{3 i},-$ inertial coefficients for the engine speed of the MTU engine, hourly air flow rate, and cyclic fuel supply; $\mathrm{n}_{0}, \mathrm{G}_{\mathrm{a} 0}, \mathrm{~g}_{\mathrm{T} 0}$ - the initial value of the rotational speed of the crankshaft of the MTU engine, hourly air flow and cyclic fuel supply; $\mathrm{K}_{\mathrm{n} 2}, \mathrm{~K}_{\mathrm{g} 2}, \mathrm{~K}_{\mathrm{a} 2}-$ amplification factors of the MTU engine crankshaft rotation, hourly air flow rate and cyclic supply from a change in engine torque according to the regulatory stationary characteristics; $\Delta \mathrm{M}_{\mathrm{c}}-$ load increment, $\mathrm{Nm}$.

When solving differential equations, we take into account that the law of change in the resistive torque should most accurately describe the change in the resistive torque of the $\mathrm{MTU}$, which is brought to the crankshaft of the engine.

To find the values of the coefficients of differential equations, it is necessary to solve it taking into account the results of the obtained experimental data. Differential equations were solved numerically using a computer and a special program.

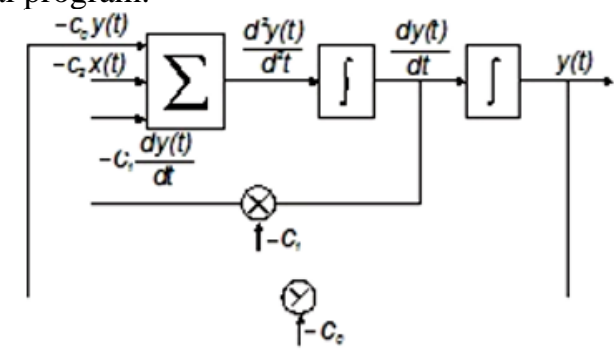

Fig. 2. Mathematical model of ICE

The effective engine power is determined by the formula.

$$
N_{e}=B_{N} \cdot\left(M_{e 0} \pm \Delta M_{c} \mp J_{n p} \frac{d \omega}{d t}\right) \cdot\left(n_{0} \mp \Delta n\right),
$$

where $\mathrm{B}_{\mathrm{N}}-$ proportionality coefficient,

$$
B_{N}=\frac{\pi}{30000}=0.000105 \text {; }
$$

$\Delta \mathrm{n}$ - change of turns of a shaft of the engine, $\Delta \mathrm{n}=\mathrm{f}(\mathrm{t}$, $\left.\Delta \mathrm{M}_{\mathrm{c}}\right)$.

$$
M_{e 0}=\frac{r_{r}}{i_{t r} \cdot \eta_{t r}} \cdot\left[G_{t r}(f \cdot \operatorname{Cos} \beta+\operatorname{Sin} \beta)+K_{V} \cdot F \cdot V_{t r}^{2}+P_{h 0}\right],
$$

where $r_{r}-$ rolling radius of the driving wheel, $m ; i_{t r}-$ ransmission gear ratio; $\eta_{\text {tr }}-$ tractor transmission 
efficiency; $\mathrm{G}_{\mathrm{tr}}$ the weight of the tractor, $\mathrm{N} ; \mathrm{f}-$ the rolling resistance coefficient of the tractor; $\beta$ - the angle of inclination of the field surface, degrees; $\mathrm{K}_{\mathrm{V}}-$ tractor streamlining coefficient, $\mathrm{N} \bullet \mathrm{s} 2 / \mathrm{m} 4 ; \mathrm{F}$ - tractor crosssectional area, $\mathrm{m}^{2} ; \mathrm{V}_{\mathrm{tr}}-$ tractor speed, $\mathrm{m} / \mathrm{s} ; \mathrm{P}_{\mathrm{h} 0}-$ initial force on the hook of the tractor, $\mathrm{N}$.

$$
\Delta M_{r}=\frac{r_{r}}{i_{c s g} \cdot i_{0} \cdot i_{f} \cdot \eta_{T}} \cdot K_{s} \cdot A \cdot B_{V} \cdot t_{1},
$$

$\mathrm{I}_{\mathrm{csg}}$ - gear transmission ratio of the change speed gearbox; $\mathrm{i}_{0}$ - gear transmission ratio of the rear drive; $\mathrm{i}_{\mathrm{f}}-$ gear transmission ratio of the final drive; $K_{\mathrm{s}}-$ soil resistivity, $\mathrm{Pa}$; $\mathrm{A}$ - working width of the agricultural implements, $\mathrm{m} ; \mathrm{B}_{\mathrm{V}}$ - depth of penetration of agricultural implements, $\mathrm{m} / \mathrm{s} ; \mathrm{t}_{1}$ - the time of deepening of agricultural implements, $s$.

Indicators of the efficiency of the MTU engine are: Hourly fuel consumption, $\mathrm{kg} /$ hour.

$$
G_{f}=B_{g}\left(g_{c 0} \pm \Delta g_{c}\right) \cdot\left(n_{0} \mp \Delta n\right),
$$

where $\mathrm{B}_{\mathrm{g}}$ - the coefficient of proportionality, $\mathrm{Bg}=0.03$; $\Delta \mathrm{g}_{\mathrm{c}}$ - change in fuel cycle, $\Delta \mathrm{g}_{\mathrm{c}}=\mathrm{f}\left(\mathrm{t}, \mathrm{n}, \mathrm{h}, \Delta \mathrm{M}_{\mathrm{c}}\right)$.

Specific fuel consumption, $\mathrm{g} / \mathrm{kW} \cdot$ hour.

$$
g_{e}=1000 \frac{G_{f}}{N_{e}},
$$

Hourly air consumption, $\mathrm{kg} / \mathrm{h}$.

$$
G_{a}=G_{a 0} \mp \Delta G_{a},
$$

where $\Delta \mathrm{G}_{\mathrm{a}}$ - change in hourly air flow, $\Delta \mathrm{G}_{\mathrm{a}}=\mathrm{f}(\mathrm{t}, \mathrm{n}$, ).

The excess air coefficient for a diesel engine is determined by the formula.

$$
\alpha=\frac{G_{a}}{14.5 \cdot G_{f}},
$$

The delay time of a change in the parameter perturbation is determined experimentally. Theoretical studies of the performance of the MTU engine led us to the following conclusions:

The theoretical dependencies describing the influence of the nature of the unsteady load (taking into account the excess air coefficient) on the changes in the MTU engine are considered. This allows us to determine the coefficients of differential equations, the fuel cycle, the change in the engine speed and hourly air flow rate.

Theoretical principles to modernize the air supply regulation system in MTU engines could be applied.

\section{Results}

Figures 3-7 show the results of experimental studies of the effect of the coefficient of excess air on engine performance during a load surge.

Analysis of the effects of unsteady load taking into account the coefficient of excess, air on the performance of the MTU engine. During load surge.

1. The delay time for changing the engine speed of the MTU engine increases to $0.18 \mathrm{~s}$. at $\alpha=1.23$ and $\alpha=$ 1.43 , compared with $\alpha=1.33-0.15 \mathrm{~s}$.

2. The MTU engine power change occurs more intensively at $\alpha=1.23$ than at $\alpha=1.43$ by $0.8 \mathrm{~s}$, but at the end of the transition process the power becomes 1.2 $\mathrm{kW}$ less compared to the base engine.
3. The torque of the crankshaft of the MTU engine at $\alpha=1.23$ increases faster intensively (by $0.7 \mathrm{~s}$ ) than at $\alpha=$ 1.43 .

4. Specific fuel consumption decreases more intensively by $1 \mathrm{~s}$. for $\alpha=1.23$ than for $\alpha=1.43$.

5 . The change in hourly fuel consumption is almost the same, but at the end of the transition process at $\alpha=$ 1.23 it is $0.4 \mathrm{~kg} / \mathrm{h}$ more than at $\alpha=1.43$.

6 . The change in the hourly air flow occurs more intensively by $0.7 \mathrm{~s}$ at $\alpha=1.43$ than at $\alpha=1.23$.



Fig. 3. Graph of the effect of the coefficient of excess air on the engine speed at a load surge



Fig. 4. Graph of the effect of the coefficient of excess air on engine torque during load surge

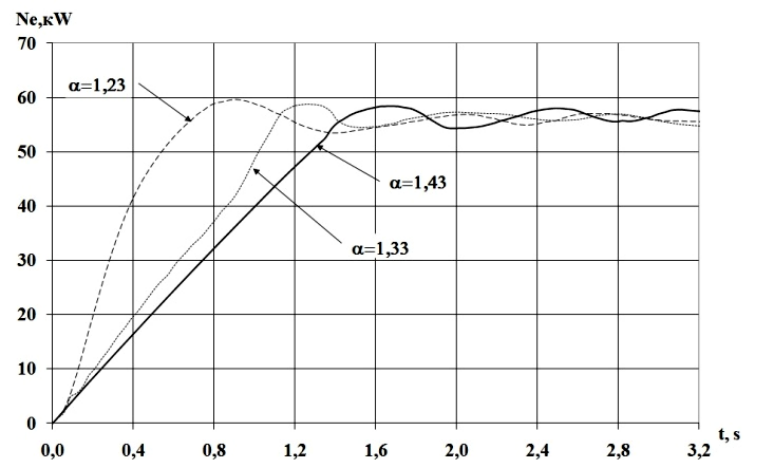

Fig. 5. Graph of the effect of the coefficient of excess air on engine power during load surge. 




Fig. 6. Graph of the effect of the coefficient of excess air on the specific fuel consumption during load transfer.

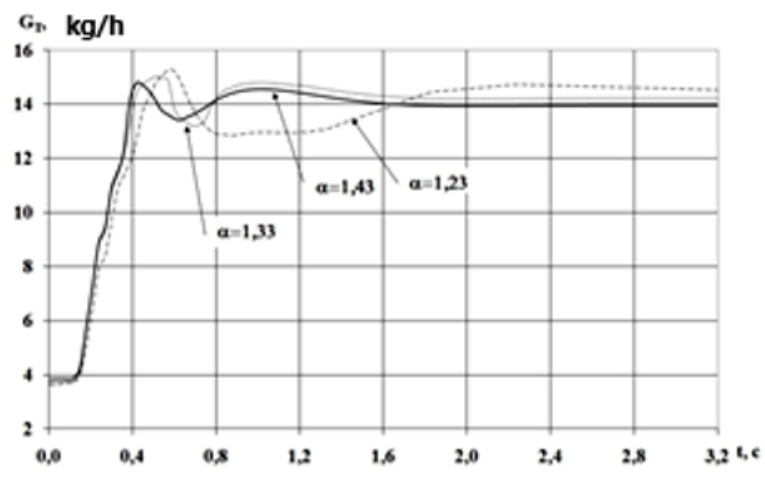

Fig. 7. Graph of the effect of the coefficient of excess air on the hourly fuel consumption during load surge.

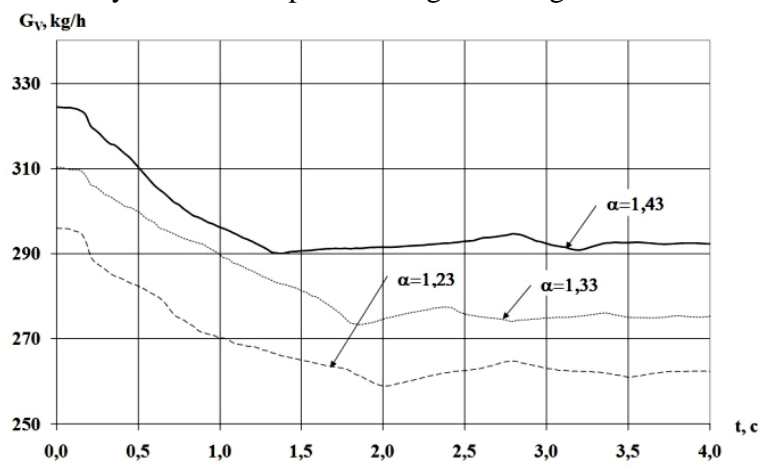

Fig. 8. Graph of the effect of the coefficient of excess air on the hourly air flow during load surge.

Figures 9 ... 11 show graphs of convergence of theoretical and field studies of MTU engine performance under unsteady load.

When testing the adjustment of the coefficient of excess air corresponded to the parameters of the manufacturer.

Analyzing this graph, we can say that the theoretical and experimental values have good convergence, and the slight deviation in the initial period is explained by the fact that during the theoretical calculations the power spent on rolling the MTU across the field was not taken into account.

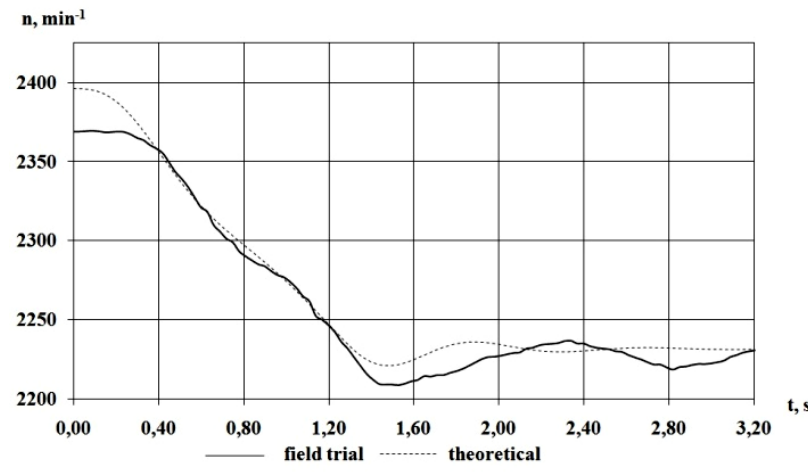

Fig. 9. Graph of changes in the revolutions of the crankshaft of the MTU engine during a load surge.

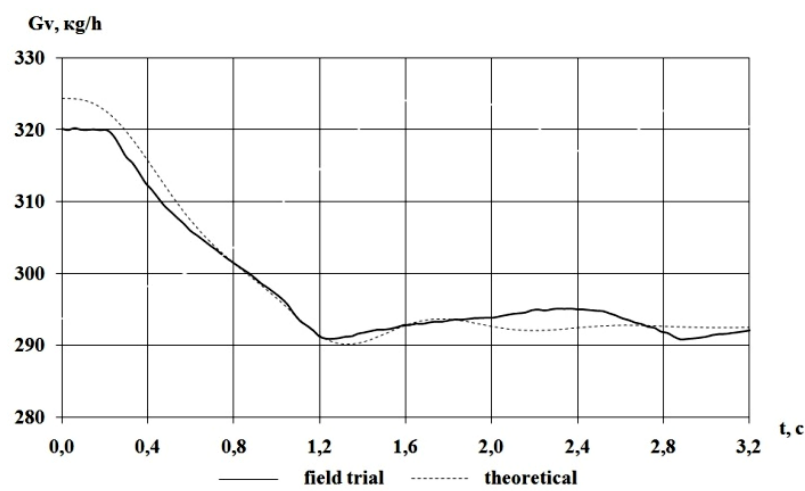

Fig. 10. Graphs of changes in the hourly air flow rate of the MTU engine during a load surge.

The initial values of the hourly air flow rate are somewhat lower during field tests compared to theoretical ones, which is due to the lower initial engine speed, which in turn decreases due to the fact that part of the engine power is spent on rolling the tractor.



Fig. 11. Graphs of changes in cyclic fuel supply during load surge

Graphs of field and theoretical studies have good convergence. The difference in the initial period is due to not a significant difference in the engine speed of the MTU engine.

\section{Conclusion}

Improving the working processes of the MTU engine is associated with the air supply system when working with 
an unsteady load will reduce engine power loss by $3 \ldots$ $4 \%$ and reduce specific fuel consumption by $4 \ldots 5 \%$.

Experimental (field) and theoretical studies have confirmed the adequacy of theoretical calculations with experimental data. Deviation in rotational speed of the crankshaft of the MTU engine is not more than 3\%; cyclic fuel supply not more than $3 \%$, hourly air consumption not more than $4 \%$.

\section{References}

1. V.N. Boltinsky, Work of the tractor engine under unsteady load (Selkhozizd, Moscow, 1959)

2. A.K. Yuldashev, The dynamics of the working processes of the engine of machine - tractor units (Tatar book, Kazan, 1980)

3. A.K. Yuldashev, Development of ways of dynamic qualities of automotive diesel engines, Doctoral dissertation (Kazan, 1985)

4. V.I. Krutov, I.P. Sporysh, V.D. Yunoshev, Fundamentals of the theory of automatic regulation (Mechanical Engineering, Moscow, 1969)

5. V.P. Antipin, A.A. Shevtsov, Character of the influence of engine power on fuel consumption in an unsteady mode Engine building 10, 45-46 (Moscow, 1986)

6. R.R. Galiullin, Increase of effective indicators of tractor diesel engines with electronic fuel supply. Doctoral dissertation (Ufa, 2009)

7. F.Kh. Khaliullin, V.M. Medvedev, R.R. Shiriazdanov, A mathematical model for determining the operational performance of power plants of mobile machines in transient operating modes Bulletin of the Kazan State Agrarian University 10 1(35), 71-74 (2015)

8. S.A. Sinitsky, The influence of unsteady load on the performance of the MTU engine in Actual problems of mechanization of agriculture: materials of the anniversary scientific and practical conf. "Higher agricultural engineering education in Udmurtia is 50 years old." 127-130 (Izhevsk, 2005)

9. A.K. Yuldashev, V.M. Medvedev, S.A. Sinitsky, K.M. Latypov, Ways to increase the efficiency of using internal combustion engines of cars and tractor units in operating conditions Bulletin of the Moscow State Agroengineering University named after V.P. Goryachkina 1(21), (2007)

10. S.A. Sinitsky, The influence of the load of the machine-tractor unit on engine performance in operating conditions. Candidate dissertation (Kazan, 2005)

11. F.F. Khokhlov, The effect of transients on the weekend indicators of a tractor diesel in Improving the technical and economic indicators of tractors 88-94 (Chelyabinsk Institute of agriculture mechanization and electrification, 1985)

12. V.M. Arkhangelsky, K. D. Derbaremdiner, V. I. Bednev, S. S. Epstein, Determining the efficiency of the engine in acceleration modes in the conditions of a modeling stand Automobile industry 8, 6-8 (1974)

13. V.G. Patoka, S.A. Sinitsky, A.K. Yuldashev, The influence of the coefficients of differential equations on the transient characteristics of the MTU engine in Actual problems of mechanization of agriculture: materials of the anniversary scientific - practical conf. "Higher agricultural engineering education in Udmurtia is 50 years old." 143-147 (Izhevsk, 2005)

14. S. E. Selifanov, D. A. Vakhrameev, The main provisions of the development of a mathematical model of the transient process of the engine when using advanced load control in Materials of the scientific conf. "Problems of mechanization of agricultural production of the Republic of Tatarstan" (Kazan, 1999)

15. S. E. Selifanov, D. A. Vakhrameev, N. K. Maksimov, Two-pulse regulation of agricultural tractor engines in Materials of the XIX scientificpractical conf. of the Izhevsk State Agricultural Academy (Izhevsk, 1999)

16. V.M. Medvedev, I.R. Ahmetzyanov, R.R. Shiriyazdanov, F.K. Khaliullin, Operating conditions of the D-240 Engine based dual fuel gasdiesel engine of the agricultural tractor in "European Conf. on Innovations in Technical and Natural Sci.» Proc. of the $2^{\text {nd }}$ Int. sci. conf. (May 12, 2014). («East West» Association for Advanced Studies and Higher Education GmbH, Vienna, 2014)

17. F. Kh. Khaliullin, V.M. Medvedev, The operator form of solving equations for the model of power plants of mobile machines Bulletin of Kazan State Agrarian University 9 2(32), 75-77 (2014)

18. F.Z. Gabdrafikov, S.B. Shamukaev, E.P. Mekhonoshin, Improving the efficiency of diesel engines in transient modes by electronic control of fuel supply Mechanization and electrification of agriculture 7, 19-20 (2015)

19. M.A. Abramov, Improving the efficiency of the functioning of a diesel engine of a tractor unit by electronic regulation of fuel supply. Candidate dissertation abstract (St. Petersburg-Pushkin, 2012) 